\title{
Posttranscriptional regulation of gene expression-adding another layer of complexity to the DNA damage response
}

\author{
Jorge Boucas ${ }^{1+}$, Arina Riabinska ${ }^{1+}$, Mladen Jokic ${ }^{1,2}$, Grit S. Herter-Sprie ${ }^{1}$, Shuhua Chen ${ }^{1}$, \\ Katja Höpker ${ }^{3}$ and H. Christian Reinhardt ${ }^{1 *}$ \\ Division of Hematology and Oncology, Center for Internal Medicine, University Hospital of Cologne, Cologne, Germany \\ 2 Division of Molecular Medicine, Rudjer Boskovic Institute, Zagreb, Croatia \\ ${ }^{3}$ Division of Nephrology, Center for Internal Medicine, University Hospital of Cologne, Cologne, Germany
}

Edited by:

Antonio Porro, École Polytechnique Fédérale de Lausanne, Switzerland

Reviewed by:

Philipp Kaldis, A*STAR (Agency for Science, Technology and Research), Singapore

Kotb Abdelmohsen, National

Institutes of Health, USA

\section{*Correspondence:}

H. Christian Reinhardt, Division of Hematology and Oncology, Center for Internal Medicine, University Hospital of Cologne, Kerpener

Str. 62, 50937 Cologne, Germany. e-mail: christian.reinhardt@ uk-koeln.de

tThese authors equally contributed to this work.
In response to DNA damage, cells activate a complex, kinase-based signaling network to arrest the cell cycle and allow time for DNA repair, or, if the extend of damage is beyond repair capacity, induce apoptosis. This signaling network, which is collectively referred to as the DNA damage response (DDR), is primarily thought to consist of two components - a rapid phosphorylation-driven signaling cascade that results in immediate inhibition of Cdk/cyclin complexes and a delayed transcriptional response that promotes a prolonged cell cycle arrest through the induction of Cdk inhibitors, such as p21. In recent years a third layer of complexity has emerged that involves potent posttranscriptional regulatory mechanisms that control the cellular response to DNA damage. Although much has been written on the relevance of the DDR in cancer and on the post-transcriptional role of microRNAs (miRs) in cancer, the post-transcriptional regulation of the DDR by non-coding RNAs and RNA-binding proteins (RBPS) still remains elusive in large parts. Here, we review the recent developments in this exciting new area of research in the cellular response to genotoxic stress. We put specific emphasis on the role of RBPs and the control of their function through DNA damage-activated protein kinases.

Keywords: MAPKAP-kinase 2, HuR, hnRNP A0, TIAR, PARN, DNA damage response, cell cycle checkpoint

\section{CELLS ACTIVATE A COMPLEX SIGNALING NETWORK} IN RESPONSE TO DNA DAMAGE

All life on earth must resist a constant assault on its genomic integrity by various endogenous and exogenous sources. Stalled replication forks or incomplete DNA replication during S-phase, and a plethora of different DNA lesions, such as those ubiquitously induced by UV, ionizing radiation (IR), or reactive oxygen species, as well as those intentionally provoked by treatment with chemotherapeutic agents, or radiation therapy used in cancer patients, activate a complex, kinase-based signaling network, which is collectively referred to as the DNA damage response (DDR). Activation of the DDR network through genotoxic lesions triggers signal transduction cascades to activate cell cycle checkpoints, which prevent further progression through the cell cycle as long as the lesions persist (Jackson and Bartek, 2009).

The DDR can be subdivided into two major kinase signaling branches: the ATM pathway, acting through the downstream effector kinase Chk2 and the proximal DDR kinase ATR, acting through Chk1. Some crosstalk exists between the ATM/Chk2 and ATR/Chk1 pathways, particularly when signaling through one pathway is partially or totally deficient (Kastan and Lim, 2000; Abraham, 2001; Shiloh, 2001, 2003; Bartek and Lukas, 2003). Normally however, the pathways appear to have distinct functions with only partial functional overlap in response to particular forms of DNA damage, especially at later stages in the cell cycle (Jazayeri et al., 2006). Different types of genotoxic stress are preferentially channeled through one or the other of these two pathways. The ATM/Chk2 pathway is activated primarily in response to DNA double strand breaks (DSBs), such as those formed by IR or topoisomerase- 2 inhibitors, such as etoposide or doxorubicin, while the ATR/Chk1 pathway is activated by bulky DNA lesions induced by UV and in response to replication fork collapse during S-phase (Zhou and Elledge, 2000; Abraham, 2001).

A major target of both the ATM/Chk2 and the ATR/Chk1 branch of the DDR are members of the Cdc25 family of dual specificity phosphatases. Phosphorylation-dependent inhibition of Cdc25 prevents activation of the Cdk-cyclin complexes that mediate transition from $\mathrm{G}_{1}$ into $\mathrm{S}$-phase, progression through S-phase and mitotic entry, thus establishing $G_{1}$, intra-S-phase, and $\mathrm{G}_{2} / \mathrm{M}$ cell cycle checkpoints (Donzelli and Draetta, 2003; Rudolph, 2007). Cdc25A is required for activation of Cdk2-Cyclin $\mathrm{E}$ and A complexes that govern S-phase entry and progression. Chk1-mediated phosphorylation of Cdc25A creates a phosphodegron motif, resulting in $\mathrm{SCF}^{\beta-T r C P}$-dependent ubiquitination and subsequent proteasomal degradation, as the major mechanism of inhibition (Jin et al., 2003). Cdc25B and C are required for activation of Cdk1-cyclin B complexes mediating mitotic entry. Upon DNA damage Chk1 and 2 phosphorylate Cdc25B and $\mathrm{C}$, creating phosphoepitopes that are recognized and bound by phosphopeptide-binding 14-3-3 proteins (Donzelli and Draetta, 2003; Harper and Elledge, 2007). 14-3-3 serves as a molecular 
chauffeur resulting in cytoplasmic translocation and sequestration of the complexes, preventing Cdc25B/C from activating Cdk1-cyclin B complexes.

We and others have recently identified a third cell cycle checkpoint effector kinase pathway that is governed by $\mathrm{p} 38 \alpha / \beta$ dependent activation of MK2 (Bulavin et al., 2001; Manke et al., 2005; Raman et al., 2007; Reinhardt et al., 2007, 2010; Reinhardt and Yaffe, 2009). This pathway is activated in response to UV and the commonly used chemotherapeutic drugs cisplatin, camptothecin and doxorubicin (Manke et al., 2005; Raman et al., 2007; Reinhardt et al., 2007). We showed that ATM and ATR are required to activate the $\mathrm{p} 38 / \mathrm{MK} 2$ module after doxorubicin and cisplatin (Reinhardt et al., 2007). In a series of experiments, we showed that MK2 functions as a downstream checkpoint effector kinase that is critical for cellular survival following DNA damage, specifically in cells and tumors that had lost the prominent tumor suppressor p53 (Reinhardt et al., 2007, 2009; Reinhardt and Yaffe, 2009). MK2 is required to prevent $G_{1} / S$, intra-S phase and $G_{2} / M$ transition after cisplatin and doxorubicin in p53-deficient cells (Reinhardt et al., 2007). Intriguingly, MK2 appears to operate in a pathway that is redundant with, but independent of Chk1 (Manke et al., 2005; Reinhardt et al., 2007). Using oriented peptide library screening (OPLS), we determined the amino acid specificity for MK2 phosphorylation and found that it is identical to the optimal sequences selected by the checkpoint kinases Chk1 and Chk2 (Manke et al., 2005; Reinhardt et al., 2007). This finding suggested that all three kinases might share a pool of common substrates. Indeed, we could show that MK2 directly phosphorylates Cdc25A and is required for its DNA damage-dependent degradation, resulting in a $G_{1} / S$ arrest after cisplatin and $U V$ (Manke et al., 2005; Reinhardt et al., 2007). In response to doxorubicin, MK2 phosphorylates Cdc25B and C on known Chk1 sites, generating functional 14-3-3 binding sites and resulting in a $\mathrm{G}_{2} / \mathrm{M}$ arrest (Reinhardt et al., 2007). These results suggest that cells lacking a functional p53 response recruit a general stress response network-p38/MK2 - to arrest the cell cycle after genotoxic stress. More importantly, this requirement for the p38/MK2 network in p53-deficient tumors, rationalizes the use of MK2 inhibitors as chemosensitizing agents that are based on the synthetic lethal interaction between the corresponding genes TP53 and MAPKAPK2 (Reinhardt et al., 2009).

In addition to the activation of this canonical DDR kinase network, which brings about numerous changes in the cellular signaling circuitry occur as a consequence of posttranslational modifications of proteins functioning within the DDR network through phosphorylation, ubiquitylation or sumoylation (Reinhardt and Yaffe, 2009), the pattern of mRNA expression also undergoes significant changes after DNA damage (Rieger and Chu, 2004; Reinhardt et al., 2011). For instance, human lymphoblastoid cells from healthy adults display up- or downregulation of thousands of mRNAs following exposure to IR or ultraviolet light (Rieger and Chu, 2004). Furthermore, transcriptome analysis following MMS or IR treatment showed that the expression levels of as much as $20 \%$ of genes in budding yeast showed a 2-fold or greater change (Gasch et al., 2001). These profound transcriptome alterations appear counterintuitive at first glance, as de novo transcription of genes shortly after the infliction of DNA damage might pose a certain threat. The template DNA strand used for transcription might be damaged, leading to the transcription of potentially mutated RNA. In addition, the transcription process is energy-intensive (synthesis of an RNA molecule with $n$ bases requires at least $n$ NTP molecules) and relatively time-consuming. Specifically, the temporal component imposes a pivotal risk, if the protein product derived from the transcribed mRNA was rapidly needed for cell cycle arrest, DNA repair or the induction of apoptosis. Perhaps not surprisingly, DNA damage, such as that induced by UV-C irradiation, has been shown to trigger a transient repression of transcriptional activity in eukaryotic cells (Vichi et al., 1997; Rockx et al., 2000). Several molecular mechanisms have been implicated in mediating this DNA damage-induced global repression of transcriptional activity. RNA Pol II becomes hyperphosphorylated in response to genotoxic stress and is thus prevented from entering pre-initiation complexes at promoter sites (Rockx et al., 2000; Svejstrup, 2002). Furthermore, in vitro evidence suggests that the TATA-binding protein TBP is sequestered onto damaged DNA, reducing its availability for transcription (Vichi et al., 1997; Svejstrup, 2002). The transcriptional repression that is mediated through these molecular pathways varies depending on the type and intensity of DNA damage and is reverted upon completion of DNA repair (Svejstrup, 2002). However, this DNA damageinduced repression of transcriptional activity immediately poses the question how cells accomplish the DNA damage-induced changes in mRNA expression, which have clearly been demonstrated by numerous groups?

\section{POSTTRANSCRIPTIONAL REGULATION OF THE DNA DAMAGE RESPONSE}

As transcription is globally repressed upon DNA damage, additional mechanisms that regulate protein biosynthesis from preexisting pools of mRNA become critically important to allow an appropriate cellular DDR. Two posttranscriptional regulatory mechanisms are at play to control protein expression following genotoxic stress: (1) selective mRNA stabilization or decay and (2) regulation of translation. Both of these mechanisms critically hinge on the function of RNA-binding proteins (RBPs) and non-coding RNAs, which modulate mRNA stability, transport and translatability through direct interactions with their client mRNAs. Thus, in addition to a well-studied plethora of posttranslational modifications, including phosphorylation, ubiquitination, methylation, acetylation, and others (Harper and Elledge, 2007; Jackson and Bartek, 2009), posttranscriptional control mechanisms are emerging as a new layer of regulation within the complex DDR signaling network.

Intriguing in this regard is data that emerged from a recent phospho-proteomic screen aiming to identify novel ATM/ ATR/DNA-PK substrates. The largest subset of substrates identified in these experiments were proteins linked to RNA and DNA metabolism, and specifically proteins involved in posttranscriptional mRNA regulation (Matsuoka et al., 2007). In addition, gene products responsible for nucleic acid metabolism, particularly those involved in mRNA binding and processing, have recently been identified as the largest subset of "hits" in an RNAi-mediated loss of function screen to identify modulators of DNA damage 
signaling (Paulsen et al., 2009). Furthermore, data provided by Gorospe and co-workers re-enforced the role of posttranscriptional regulatory circuits in the control of a large fraction of the transcriptome in response to genotoxic stress (Fan et al., 2002). Specifically, cDNA expression arrays were employed to gauge the relative contribution of transcription and mRNA turnover to overall changes in gene expression after a variety of cellular stresses, including UV-C irradiation. In essence, a comparison of cDNA hybridization patterns of newly transcribed mRNAs derived from nuclear run-on assays, and steady state mRNA pools derived from whole cell lysates was performed. These experiments revealed that approximately $50 \%$ of the changes in mRNA steady state levels that were observed after cellular stress, were attributable to mRNA turnover (stabilization/decay), while the remaining $\sim 50 \%$ were due to altered transcription. Lastly, applying a mass spectrometry-based interactome screen, Yaffe and colleagues identified proteins involved in mRNA splicing and translation as the largest group of molecules interacting with the critical DDR protein 14-3-3 (Wilker et al., 2007). These coinciding observations, observed in very different experimental settings, highlight the potential importance of posttranscriptional regulatory mechanisms in the context of DDR signaling, and strongly argue that the DDR may extend substantially beyond the classical ATM/Chk2 and ATR/Chk1 signaling cascades detailed above.

The first links between the kinase-based canonical DDR and posttranscriptional regulatory mechanisms were established through the study of $\mathrm{p} 21^{\mathrm{Cip} 1 / \mathrm{WAF}}$ mRNA. $221^{\mathrm{Cip} 1 / \mathrm{WAF}}$ is a canonical p53 target gene and is potently induced in response to genotoxic stress (el-Deiry et al., 1993). Not only could Wang et al. show that the RBP HuR (human antigen R or ELAVL1, a member of the embryonic lethal abnormal vision-like familiy) formed a ribonucleoprotein (RNP) complex with p21 Cip1/WAF mRNA in RKO colorectal carcinoma cells following UV-C irradiation, but also that this complex formation appeared to be critical for $\mathrm{p} 21^{\mathrm{Cip} 1 / \mathrm{WAF}} \mathrm{mRNA}$ stabilization following genotoxic stress, as HuR depletion impaired p21 2 Cip1/WAF mRNA induction after UV-C (Wang et al., 2000). Further, the laboratory of A. Nebreda recently showed that $\mathrm{p} 38 \mathrm{MAPK}$ induces $\mathrm{p} 21^{\mathrm{Cip} 1 / \mathrm{WAF}}$ mRNA stabilization without significantly affecting transcription of p21 Cip1/WAF (Lafarga et al., 2009). p38MAPK-mediated phosphorylation of HuR on Thr-118 in response to IR was shown to be critical for cytoplasmic accumulation of HuR, enhanced binding to the $\mathrm{p} 21^{\mathrm{Cip} 1 / \mathrm{WAF}} \mathrm{mRNA}$ and subsequent $\mathrm{p} 21^{\mathrm{Cip} 1 / \mathrm{WAF}} \mathrm{mRNA}$ and protein accumulation (Lafarga et al., 2009). Further experiments revealed that the shuttling of $\mathrm{HuR}$ between the nucleus and the cytoplasm is tightly regulated by a variety of kinases, including Cdk1, Chk2, and MK2 (Tran et al., 2003; Abdelmohsen et al., 2007; Kim et al., 2008). recently suggested that Chk2, which shares substrate homology with MK2 (Manke et al., 2005), phosphorylates HuR on Ser-88, Ser-100, and Thr-118. This interaction is likely to occur in the nucleus, since Chk 2 and $\mathrm{HuR}$ could be coimmunoprecipitated only from nuclear extracts (Abdelmohsen et al., 2007). Phosphorylation, particularly on Ser-100 in response to genotoxic $\mathrm{H}_{2} \mathrm{O}_{2}$, decreased the binding affinity of $\mathrm{HuR}$ to its target mRNA SIRT1 (Sirtuin 1), resulting in destabilization of SIRT1 mRNA, decreased SIRT1 protein levels and increased sensitivity of WI-38 human diploid fibroblasts to the cytotoxic effects of $\mathrm{H}_{2} \mathrm{O}_{2}$. Mutation of Ser-88 and Thr-118 to Ala reduced SIRT1 mRNA binding even in the absence of $\mathrm{H}_{2} \mathrm{O}_{2}$, suggesting that phosphorylation on these sites actually promotes HuR RNP formation. It is, however, also conceivable that these particular mutations induce conformational changes that preclude effective RNA binding, since these residues are located within the RNA recognition motifs (RRMs) of HuR. Interestingly, treatment of WI-38 cells with $\mathrm{H}_{2} \mathrm{O}_{2}$ revealed that binding of wildtype $\mathrm{HuR}$ differed according to the target mRNA: binding of $\mathrm{p} 21^{\mathrm{Cip} 1 / \mathrm{WAF}}$ mRNA was increased, while decreased on SIRT1 and numerous cyclin mRNAs. However, mutation of Ser-100 to Ala generally increased the binding affinity of HuR to all mRNAs tested. These observations suggest that although Chk2 is clearly activated by $\mathrm{H}_{2} \mathrm{O}_{2}$, this activity does not translate into a uniform decrease in HuR binding affinity to its target mRNAs. One could speculate that structural features within the HuR target mRNAs or the recruitment of other RBPs into the HuR RNPs ultimately dictate the affinity of HuR to its target mRNAs. It is also possible that the Chk2 recognition motif in HuR might be masked in certain RNPs, which could preclude Chk2-mediated phosphorylation of Ser-100 in certain RNPs. These questions await further clarification.

As a member of the ELAV-like family of RBPs, HuR has strong binding affinity to mRNAs that contain so-called AU-rich elements (AREs) in their $3^{\prime}$ UTR (Dean et al., 2004). AREs act as potent mRNA destabilizing elements that target mRNA for rapid deadenylation (Chen and Shyu, 1994; Xu et al., 1997; Wilson and Treisman, 1988). AREs can be subdivided into three classes: class I and II AREs contain copies of an AUUUA pentameric repeat, called Shaw-Kamen motif (Shaw and Kamen, 1986). Class I AREs contain 1-3 scattered Shaw-Kamen motifs in the $3^{\prime}$ UTR, class II AREs contain multiple, partially overlapping AREs in their $3^{\prime}$ UTR, and class III AREs commonly lack the AUUUA pentamer, but are enriched for U-rich sequence stretches (Dean et al., 2004).

Nagamine and colleagues (Tran et al., 2003) showed that HuR binds and stabilizes the urokinase plasminogen activator (uPA) mRNA in an ARE-dependent manner. The authors went on to show that overexpression of constitutively active MK2 resulted in stabilization of ARE-containing reporter mRNAs. This effect correlated with an MK2-dependent cytoplasmic accumulation of $\mathrm{HuR}$. Furthermore, treatment with $\mathrm{H}_{2} \mathrm{O}_{2}$, a known MK2 activating stimulus, also resulted in cytoplasmic HuR accumulation. The authors demonstrated that increased binding of HuR to AREcontaining uPA mRNA and stabilization of an ARE-containing reporter mRNA in response to $\mathrm{H}_{2} \mathrm{O}_{2}$ depended on MK2 acting downstream of p38MAPK. However, no evidence suggesting that MK2 directly phosphorylates HuR in this system was presented in this study.

In contrast to the molecular effect of p38MAPK, Chk2, and MK2, Cdk1-mediated HuR phosphorylation on Ser-202 was recently shown to sequester HuR in the nucleus (Kim et al., 2008). Cdk1 inhibition promoted a cytoplasmic accumulation of HuR, while a predominately nuclear localization of $\mathrm{HuR}$ was observed under conditions of high Cdk1 activity. Furthermore, a Ser-202 to Ala mutant form of HuR was located primarily in the cytoplasm, while phospho-Ser-202 HuR could be detected almost exclusively in the nucleus. Kim et al. further showed that Cdk1-dependent 
Ser-202 phosphorylation of HuR was essential for 14-3-30 binding to HuR. However, it was never formally demonstrated that the phosphopeptide-binding protein 14-3-30 directly binds a phosphoepitope surrounding Ser-202.

Among the known DDR kinases, the p38MAPK/MK2 signaling complex probably has the strongest ties to posttranscriptional control of gene expression. Anderson and colleagues characterized the MK2-mediated regulation of the zinc finger protein Tristetraprolin (TTP), which had been shown to bind and destabilize ARE-containing mRNAs such as TNF $\alpha$ (Stoecklin et al., 2004). ARE-containing mRNAs are unstable under normal conditions and are stabilized in response to various cellular stressors, such as UV, lipopolysaccharides (LPS), or arsenite (Kedersha and Anderson, 2002). In their experiments, Anderson and colleagues showed that MK2-mediated phosphorylation of TTP on Ser-52 and Ser-178 in response to arsenite generated a phosphoepitope that was subsequently engaged by 14-3-3 (Stoecklin et al., 2004). TTP binds to ARE-containing target mRNAs and directs them to exosome-dependent degradation. TTP:14-3-3 complex formation resulted in exclusion from stress granules (SGs) and inhibition of TTP-dependent degradation of ARE-containing $\beta$-globin reporter mRNA. SGs are the morphological correlate of an abrupt, stress-induced translational arrest resulting in rapid polyribosome disassembly (Kedersha and Anderson, 2002). These cytoplasmic granules consist of a number of proteins involved in RNA metabolism, as well as stalled initiation complexes, which are bound to numerous mRNAs (Anderson and Kedersha, 2006). The mRNA molecules from disassembled, stalled polyribosomes are sorted into SGs where the fate of each individual messenger is determined by RBPs that either promote RNA stabilization or decay (Kedersha and Anderson, 2002; Kedersha et al., 2005). SG proteins, such as TIA-1 and HuR, bind to ARE-containing mRNAs, and control their stability and translation (Anderson and Kedersha, 2002, 2006; Kedersha and Anderson, 2002; Kedersha et al., 2005). As an alternative mechanism to TTP:14-3-3 complex formation, it could be shown that phosphorylation of TTP by MK2 blocks mRNA decay by inhibiting the recruitment of the CCR4-CAF1 deadenylase complex (Marchese et al., 2010).

Like TTP, BRF1, subunit of the RNA polymerase III, is an ARE-binding protein that has recently been shown to be a direct substrate of MK2. Phosphorylation of BRF1 on four distinct residues (Ser-54, Ser-92, Ser-203, and an unidentified site in the C-terminus) reduced the ability of BRF1 to promote AREmediated decay. However, the mechanistic details of this effect remain somewhat unclear (Maitra et al., 2008).

Besides TTP and BRF1, which promote ARE-mediated decay, MK2 has also been shown to directly phosphorylate hnRNP A0, a protein that specifically interacts with ARE-containing mRNAs, exerting a stabilizing effect on its RNA targets. Rousseau et al. (2002) identified hnRNP A0 (heterogeneous nuclear RNP A0) as a protein with binding affinity for the AREs in the $3^{\prime}$ UTR of TNF $\alpha$ in macrophage lysates. They further showed that MK2 phosphorylates hnRNP A0 on Ser-84 following LPS treatment. Pharmacological inhibition of p38MAPK abrogated hnRNP A0 binding to its MIP-2 (macrophage inflammatory protein 2) client mRNA and impaired MIP-2 mRNA stability and protein induction. Together these findings suggest that MK2-dependent phosphorylation of hnRNP A0 is required for mRNA binding and stabilization.

A number of other RBPs have been identified as MK2 substrates in vitro, however, the functional relevance of these phosphorylation events remains elusive and awaits further investigation. For example, Bollig and colleagues identified PABP1 (Polyadenylate-binding protein 1) as a GM-CSF (Granulocyte macrophage colony-stimulating factor) ARE-binding protein, which can be efficiently phosphorylated by $\mathrm{MK} 2$ in vivo (Bollig et al., 2003). Whether this phosphorylation takes place in vivo and what influence it might have on GM-CSF mRNA stability or translation remains unclear.

Although, defects in RBPs have been associated with a large number of diseases, our current knowledge is largely still restricted to canonical RNA binding domains and target sequences (Lukong et al., 2008; Cooper et al., 2009; Darnell, 2010). However, major progress is currently being made in our understanding of RBP biology, similar to the extensive achievements concerning the role of microRNAs (miRs) in the posttranscriptional regulation of target mRNAs. Considerable accomplishments in this field were obtained from studies devoted to the systematic discovery of structural elements governing stability of mammalian mRNAs, the generation of an atlas of mammalian RBPs and the identification of target RNAs via high-throughput sequencing of cross-linked RNPs after immunoprecipitation (Hafner et al., 2010; Zhang and Darnell, 2011; Castello et al., 2012; Goodarzi et al., 2012).

\section{MicroRNA-MEDIATED REGULATION OF THE DNA DAMAGE RESPONSE}

In addition and complementary to regulation of mRNA stability and translation by RBPs, posttranscriptional control is potently exerted by miRs. These recently discovered, yet ubiquitous molecules, 18-24 nucleotides in length, regulate the stability and/or translation of their target mRNAs by forming imperfect Watson-Crick base pairs within the $3^{\prime}$ UTR. By virtue of this interaction, the microRNA recruits a protein complex referred to as miRISC (miRNA-induced silencing complex) that exerts translational repression by a mechanism that is not yet fully understood. Recently, reported data strongly suggests that destabilization of target mRNAs, instead of translational repression, is the predominant mechanism for reduced protein output (Guo et al., 2010). The minimal protein components of miRISC required for microRNA-mediated this repression are Argonaute (AGO; principally AGO2 in mammals and AGO1 in flies) and TNRC6 (trinucleotide repeat containing 6)/GW182 (glycine-tryptophan protein of $182 \mathrm{kDa}$ ) (Guo et al., 2010). One, mechanism of microRNA function that has been proposed is the sequestration of their target mRNAs in sub-cellular compartments that prevent their access to the protein synthesis machinery (Cannell et al., 2008). Two, such compartments implicated in microRNA control are SGs and P-bodies (PBs), both related structures acting as sites of triage for repressed mRNA molecules (Cannell et al., 2008; Buchan and Parker, 2009). The notion that SGs may play an important role for the DDR arises from a study by Pothof et al., who showed that UV-induced DNA damage caused a transient localization of AGO2 to SGs and that cells 
depleted of AGO2 are hypersensitive to UV-irradiation (Pothof et al., 2009). Furthermore, Zeng et al. demonstrated that MK2 can efficiently phosphorylate AGO2 on Ser-387 and this reaction was induced in HEK293T cells over-expressing AGO2 after treatment with sodium arsenite (Zeng et al., 2008), a known activator of the p38MAPK/MK2 pathway. Besides, examining immortalized human non-small cell lung carcinoma cells (NCI-H1299), the group showed that mutation of Ser-387 to alanine or pharmacological inhibition of p38MAPK reduced arsenite-induced AGO2 recruitment into PBs. This points to a potential role for MK2 signaling in the formation of SGs and PBs.

In addition to the global regulation of the DDR by AGO2, specific miRNAs have been shown to be vitally important for cells to mount a functional DDR. The first example found were the miRNAs of the miR-34 family (miR-34a, miR-34b, and miR-34c), which were simultaneously identified as p53 transcriptional targets by several groups (Chang et al., 2007; Corney et al., 2007; He et al., 2007; Tarasov et al., 2007). These miRNAs appear to act as critical regulators of the DDR by repressing target mRNAs that regulate the cell cycle and apoptosis. Concretely, data presented by Raver-Shapira et al. indicates that inhibition of miR-34a, the most pro-apoptotic member of the miR-34 family, prevented etoposide-induced cell death to the same extent as p53 depletion, suggesting that miR-34a is a potent mediator of p53-mediated apoptosis in this context (Raver-Shapira et al., 2007). The ability of miR-34a to induce apoptosis may be attributable to its ability to repress the anti-apoptotic protein BCL-2 via an interaction in the $3^{\prime}$ UTR of BCL-1 mRNA (Bommer et al., 2007). However, Yamakuchi et al. showed that miR-34a represses SIRT1 through its $3^{\prime}$ UTR and that over-expression of SIRT1 rescued miR-34a-induced apoptosis (Yamakuchi et al., 2008), suggesting that SIRT1 is a functionally important target in that system. In contrast to miR-34a, miR-34b/c do not seem to regulate cell death. Rather, these two highly homologous miRNAs inhibit cell cycle progression in response to DNA damage primarily by repressing the proto-oncogene $C-M Y C$ in both a p53-dependent and -independent manner (Cannell and Bushell, 2010; Cannell et al., 2010).

Since the initial finding of miR-34, several other miRNAs regulating events both proximal and distal to the initial DNA lesion, have been implicated in the DDR. WIP1 (wild-type p53-induced phosphatase 1), a key phosphatase targeting critical DDR components, such as p53, ATM, and H2AX for dephosphorylation, is also the target of a miRNA (Takekawa et al., 2000; Lu et al., 2005; Shreeram et al., 2006). Specifically, the experiments performed by Zhang et al. (2010) revealed that miR-16, a tumor suppressor miRNA frequently found to be deleted in chronic lymphocytic leukemia (CLL), inhibits WIP1 translation (Calin et al., 2002, 2004; Zhang et al., 2010). According to the authors, WIP1 mRNA levels rapidly increase following DNA damage, while WIP1 protein fails to accumulate. Further, they went on to show that miR-16 levels augment rapidly in response to neocarzinostatin, consequently prevent WIP1 protein accumulation and thus allowing ATM phosphoryaltion to be maintained. At later stages, likely when DNA repair is complete, miR-16 levels decrease, WIP1 protein accumulates again and ATM is dephosphorylated (Zhang et al., 2010). These observations are particularly pertinent in the context of p53 signaling: as well as transcriptionally regulating miR-34, p53 also controls the maturation of certain miRNAs including miR-16 in a posttranscriptional manner (Suzuki et al., 2009). At birth, miRNAs are long primary transcripts termed pri- miRs and are processed in the nucleus by an enzyme called Drosha to become a pre-microRNA (60-70 nucleotides in length). This pre-microRNA is further exported to the cytoplasm and subjected to the RNAse III enzyme Dicer for final processing (18-24 nucleotides). Interestingly, Suzuki et al. demonstrated that p53 forms a complex with Drosha by virtue of an interaction with the DEAD-box RNA helicase p68 (a.k.a DDX5) to augment conversion of pri-miR-16 (amongst others) in a DNA damage-dependent manner (Suzuki et al., 2009). Considering the observation that WIP1 is also a p53 target gene (Fiscella et al., 1997), allows us to hypothesize on the following scenario: p53 transcriptionally induces WIP1 and posttranscriptionally induces miR-16, which limits WIP1 protein production. Upon completion of DNA repair, miR-16 levels decrease and lead to a rise in WIP1 protein and attenuation of ATM signaling. It is tempting to speculate that the association between p53 and p68/DDX5 is regulated by alternative DNA damage signaling pathways to those, which control p53-dependent transcription leading to differential temporal regulation of p53-mediated transcription and miRNA processing.

In addition to the above, downstream events in the DDR signaling cascade are also regulated by miRNAs. By generating cell lines deficient for miR-21, Wang et al. demonstrated that CDC25A is regulated by this miRNA via its $3^{\prime}$ UTR (Wang et al., 2009). The analyses of miR-21 deficient RKO colon cancer cells disclosed increased mitotic entry in response to IR in comparison to their wild-type counterparts. This phenomenon was largely blunted by CDC25A depletion, suggesting that miR-21 regulates a DNA damage induced $\mathrm{G}_{2} / \mathrm{M}$ checkpoint by repressing CDC25A (Wang et al., 2009). It is therefore possible that DNA damage imposes a "double-hit" inhibition on CDC25A function by restraining its translation through miR-21 and promoting its degradation through Chk1/Chk2/MK2 signaling (Reinhardt and Yaffe, 2009). However, it remains enigmatic who are the key players promoting induction of miR-21 in response to DNA damage and whether this executed at the transcriptional or posttranscriptional level.

Very recently, Gorospe and colleagues have uncovered some of the mechanisms mediating miR-519-dependent regulation of the DDR (Abdelmohsen et al., 2012). It was previously known that miR-519 inhibits cell proliferation. This group now identified two prominent subsets of miR-519-regulated mRNAs. First, miR-519 targets mRNAs encoding the DNA maintenance proteins DUT1, EXO1, RPA2, and POLE4 to repress their expression ultimately resulting in increased DNA damage and upregulation of $\mathrm{CDKN} 1 \mathrm{~A}^{\mathrm{p} 21}$. The second group of target mRNAs encoded proteins involved in calcium homeostasis, such as, ATP2C1 and ORAI1. Downregulation of these mRNAs raised cytosolic calcium levels, further increasing p21 levels. Together these alterations produced an autophagic phenotype in various cell lines.

Although, the majority of studies regarding non-coding RNA has focused on the function of miRNAs, a plethora of noncoding transcripts still awaits to be analyzed for their role in 
the DDR [for a detailed review on non-coding RNA in diverse human diseases see (Esteller, 2011)]. Recently, more than 1000 large intergenic noncoding RNAs (lincRNAs) have been reported (Khalil et al., 2009). These RNAs are evolutionarily conserved in mammalian genomes and thus presumably function in diverse biological processes (Khalil et al., 2009). Interestingly, lincRNAp21 (located near the CDKN1A gene encoding the p21 protein) is transcriptionally regulated by p53 and was also shown to interact with hnRNP-K, namely by conveying hnRNP-K to the promoter region of p53 target genes, which in turn become transcriptionally repressed (Huarte et al., 2010). This lincRNA-p21:hnRNP-K interaction was observed to be required for proper genomic localization of hnRNP-K at repressed genes and regulation of p53-mediated apoptosis (Huarte et al., 2010).

More recently, Wei and colleagues elegantly illustrated that so-called DSB-induced small RNAs (diRNAs) are transcribed from sense and antisense strands at, or close to the DSB sites in Arabidopsis and human cells (Wei et al., 2012). In Arabidopsis, the biogenesis of diRNAs required ATR, RNA Pol IV, and Dicer-like proteins. Mutations in these proteins as well as in Pol V prevented efficient DSB repair (Wei et al., 2012). Subsequently, the authors provided evidence that diRNAs are recruited by AGO2 to establish DSB repair in Arabidopsis. Furthermore, depletion of Dicer or AGO2 in human cells led to a similar decrease in DSB repair efficiency. The authors propose diRNAs to serve as guiding molecules directing chromatin modifications or the recruitment of protein complexes to DSB sites in order to ultimately facilitate DSB repair (Wei et al., 2012).

\section{GADD45 $\alpha$ IS POSTTRANSCRIPTIONALLY REGULATED IN RESPONSE TO DNA DAMAGE}

In addition to $\mathrm{p} 21^{\mathrm{Cip} 1 / \mathrm{WAF}} \mathrm{mRNA}$, which has been demonstrated to be posttranscriptionally stabilized after DNA damage, Fornace and colleagues identified Gadd45 $\alpha$ mRNA as posttranscriptionally stabilized in response to genotoxic stress (Jackman et al., 1994) (Figure 1). Gadd45 $\alpha$ is part of a family of genes consisting of Gadd $45 \alpha$, Gadd $45 \beta$, and Gadd $45 \gamma$ that is widely expressed in mammalian cells following different stress stimuli. Gadd $45 \alpha$ is induced following hypoxia, IR, oxidants, UV, and growth factor withdrawal (Zhan, 2005). Gadd45 $\alpha$ has been mechanistically linked to numerous cellular processes, including apoptosis, cell cycle arrest, nucleotide excision repair and repair-mediated DNA demethylation, maintenance of genomic stability and signaling through the p38MAPK, and JNK kinase pathways (Hollander et al., 1999; Wang et al., 1999; Smith et al., 2000; Amundson et al., 2002; Hildesheim et al., 2002; Barreto et al., 2007). Gadd45 $\alpha$ expression is rapidly induced after genotoxic stress. This transcriptional activation has initially been thought to be primarily induced by p53 (Kastan et al., 1992). In fact, p53 was the first transcription factor reported to induce Gadd $45 \alpha$ transcription and, at least in response to IR, Gadd $45 \alpha$ transcription strictly depends on p53 (Kastan et al., 1992). However, it is now clear that additional transcription factors, including WT1, Oct1, NF-YA, FoxO3a, Egr-1, and C/EBP $\alpha$ are also capable of inducing Gadd45 $\alpha$ transcription, even in the absence of p53 (Constance et al., 1996; Zhan et al., 1998; Jin et al., 2001; Takahashi et al., 2001; Tran et al., 2002; Hirose et al., 2003; Thyss et al., 2005). For example, we recently showed that Gadd $45 \alpha$ was induced in p53-deficient murine embryonic fibroblasts (MEFs) following treatment with doxorubicin (Jiang et al., 2009). In resting cells, Gadd $45 \alpha$ transcription appears to be repressed through c-Myc and a repressive complex consisting of ZBRK1 and BRCA1 (Marhin et al., 1997; Amundson et al., 1998; Bush et al., 1998; Zheng et al., 2000; Tan et al., 2004). Interestingly, c-Myc itself is translationally repressed through miR-34c via a highly conserved target-site within the $3^{\prime}$ UTR in response to etoposide-induced DNA damage. While miR-34c can be induced by p53 following genotoxic stress, Cannell et al. (2010) showed that miR-34c expression in p53-deficient cells depends on the p38MAPK/MK2 signaling complex (Cannell et al., 2010). In addition to this elaborate network of transcriptional control, Fornace and colleagues reported as early as 1994 that Gadd $45 \alpha$ mRNA is posstranscriptionally stabilized in response to UV or MMS exposure (Jackman et al., 1994). However, the molecular details of this posttranscriptional regulation remained largely obscure. These posttranscriptional regulatory mechanisms might impact on Gadd $45 \alpha$ mRNA molecules at different steps of their maturation, from their de novo synthesis as pre-mRNA until the eventual degradation or translation. These steps include premRNA splicing and maturation ( $3^{\prime}$ polyadenylation, $5^{\prime}$ capping), followed by mRNA export to the cytoplasm, sub-cytoplasmic transport, escape from ribonucleolytic cleavage and translation (Mitchell and Tollervey, 2000; Orphanides and Reinberg, 2002; Moore, 2005). Recent studies from Gorospe and co-workers have identified the RBPs AUF1 and TIAR as critical posttranscriptional regulators of Gadd $45 \alpha$ mRNA (Lal et al., 2006). Both proteins were found to form RNP complexes through a direct interaction with the $3^{\prime}$ UTR of the Gadd $45 \alpha$ mRNA in resting cells. However, when cells were exposed to UV or MMS these RNP complexes rapidly dissociated, which correlated with a substantial increase in Gadd $45 \alpha$ mRNA stability an enhanced association of Gadd $45 \alpha$ mRNA with actively translating ribosomes and increased Gadd $45 \alpha$ protein accumulation (Lal et al., 2006). When Lal et al. examined the molecular mechanisms of Gadd45 $\alpha$ repression in resting cells, they found AUF1 to render Gadd45 $\alpha$ mRNA unstable while TIAR prevented the association of Gadd $45 \alpha$ mRNA with translating polyribosomes. Thus, the combined effect of AUF1 and TIAR is a potent repression of Gadd $45 \alpha$ biosynthesis through AUF1-mediated mRNA destabilization and TIAR-dependent translational suppression at resting state. The genotoxic stress-induced dissociation of AUF1 and TIAR from the Gadd $45 \alpha$ mRNA represents a mechanism of posttranscriptional derepression resulting in mRNA stabilization and enhanced translation in response to DNA damage. Both of these posttranscriptional regulatory steps were found to be essential for proper induction of Gadd $45 \alpha$ protein levels following DNA damage (Lal et al., 2006).

The report by Lal et al. implicated AUF1 and TIAR as RBPs that are critical for the posttranscriptional de-repression of Gadd $45 \alpha$ mRNA. However, it remained unclear which molecular mechanisms underlie the DNA damage-induced dissociation of these RBPs from the Gadd45 $\alpha$ mRNA. A plausible explanation might be DNA damage-dependent phosphorylation events. Indeed, AUF1 was reported to be a phospho-protein and GSK3 $\beta$ and PKA were subsequently identified as kinases capable of AUF1 


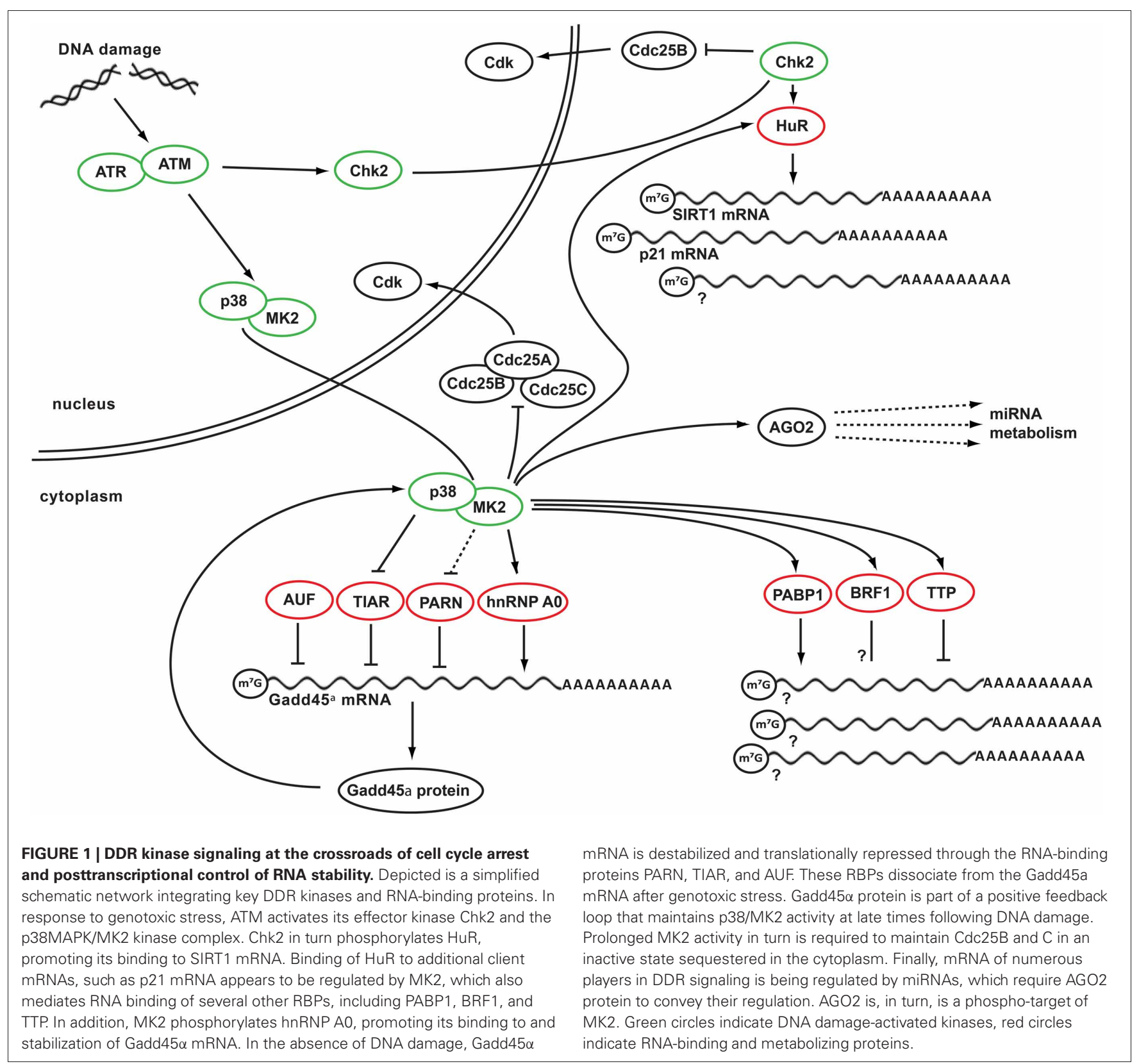

phosphorylation in vivo (Zhang et al., 1993; Wilson et al., 2003). Nonetheless, whether these phosphorylations occur in vivo following genotoxic stress persists to be elusive.

We have recently identified the p38MAPK/MK2 pathway as a critical regulator of RBPs that mediate posttranscriptional stabilization of Gadd $45 \alpha$ mRNA in response to genotoxic stress (Reinhardt et al., 2010). In analyzing the molecular details of MK2 function in response to DNA damage, we found that MK2 knockdown prevented the accumulation of Gadd $45 \alpha$ mRNA and protein in response to adriamycin. We identified the known MK2 substrate hnRNP A0 as a novel Gadd45 $\alpha$ mRNA-binding protein (Reinhardt et al., 2010). MK2-mediated phosphorylation of hnRNP A0 on Ser-84 following DNA damage was required for the formation of hnRNP A0:Gadd45 $\alpha$ mRNA RNP complexes and overexpression of a non-phosphorylatable hnRNP A0 on Ser-84 to Ala mutant prevented Gadd $45 \alpha$ mRNA and protein accumulation in response to adriamycin (Reinhardt et al., 2010). These data suggest that MK2-dependent phosphorylation of hnRNP A0 is critical for the formation of hnRNP A0:Gadd45 $\alpha$ mRNA RNP complexes, which in turn appears to be essential for the posttranscriptional stabilization of Gadd $45 \alpha$ mRNA. In addition, we found that MK2 phosphorylates Poly- $(A)$ ribonuclease (PARN) on Ser-557 in response to adriamycin (Reinhardt et al., 2010). Two major pathways of mRNA degradation exist in eukaryotes. In both cases, shortening of the poly(A) tail is the first, timelimiting, step. Three distinct protein complexes-Pan2/Pan3, or PAN complex; PARN; and the Ccr4/Pop2 complex-govern this deadenylation. After deadenylation, degradation occurs in $3^{\prime}-5^{\prime}$ 
direction through the RNase-containing exosome complex. In an independent pathway, deadenylation is followed by removal of the 7-methyl-guanosine cap of mRNAs and then proceeds in the $5^{\prime}-3^{\prime}$ direction. The mechanisms of mRNA turnover have been reviewed recently (Meyer et al., 2004). We found PARN phosphorylation on Ser-557 to be critical for prolonged Gadd $45 \alpha$ mRNA and protein expression after adriamycin (Reinhardt et al., 2010). However, the molecular details of this apparent inhibition of Gadd $45 \alpha$ mRNA degradation remain somewhat unclear. Despite our best efforts, we failed to observe any changes in PARN activity or RNA binding affinity following MK2-mediated phosphorylation on Ser-557 (Schmedding, Reinhardt, Yaffe unpublished). In addition to these MK2-mediated posttranscriptional mechanisms of Gadd $45 \alpha$ mRNA stabilization, we confirmed that TIAR dissociates from the Gadd $45 \alpha$ mRNA in response to genotoxic stress (Reinhardt et al., 2010). Furthermore, we could show that p38MAPK directly phosphorylates TIAR after adriamycin exposure, both in vitro and in vivo [(Reinhardt et al., 2010) and Morandell, Reinhardt, Yaffe unpublished]. Pretreatment of cells with the $\mathrm{p} 38 \alpha / \beta$-specific inhibitor SB203580 completely prevented the adriamycin-mediated dissociation of TIAR:Gadd $45 \alpha$ mRNA RNP complexes. Thus, we have identified three novel mechanisms of posttranscriptional Gadd $45 \alpha$ mRNA control. We identified hnRNP A0 as a critical MK2-dependent posttranscriptional inducer of Gadd $45 \alpha$ mRNA. In addition to AUF and TIAR, which have been described as posttranscriptional repressors of Gadd45 $\alpha$ mRNA, we have identified PARN as a further molecule that appears to be involved in Gadd $45 \alpha$ mRNA repression at resting state. Lastly, we could show that the DNA damage-induced dissociation of the TIAR:Gadd45 $\alpha$ mRNA RNP complex depends on p38MAPK-mediated TIAR phosphorylation.

In additional experiments we could confirm data provided by Bulavin et al. showing that Gadd $45 \alpha$ interacts with p38MAPK (Bulavin et al., 2003). Bulavin et al. further showed that Gadd45 $\alpha$ is critical for $\mathrm{H}$-ras ${ }^{\mathrm{V} 12}$-induced activation of p38MAPK. We made a similar observation in response to adriamycin-invoked genotoxic stress. RNAi-mediated knockdown of Gadd $45 \alpha$ prevented the prolonged phosphorylation and activation of MK2, likely through a lack of p38MAPK activity. MK2 remained active in control cells for at least $30 \mathrm{~h}$. However, MK2 activity dropped precipitously after $\sim 24 \mathrm{~h}$ in Gadd $45 \alpha$-depleted cells. These data suggest that the initial activation of MK2 after genotoxic stress does not depend on Gadd45 $\alpha$, but subsequent p38MAPK/MK2dependent stabilization of Gadd $45 \alpha$, through phosphorylation of TIAR, PARN, and hnRNP A0, becomes essential for maintaining MK2 activity at late times. Further experiments showed that particularly this late MK2 activity was critical to maintain checkpoint control after genotoxic stress invoked by doxorubicin through a mechanism involving Cdc25B/C inactivation. Members of the Cdc25 family of dual-specificity phosphatases are phosphorylated by the checkpoint effector kinases Chk1 and MK2 in response to DNA damage. We and others previously showed that the cell cycle arresting checkpoint function of MK2 is mediated through MK2-dependent Cdc25B/C phosphorylation and subsequent cytoplasmic sequestration (Lopez-Aviles et al., 2005; Manke et al., 2005; Reinhardt et al., 2007).

We note that MK2 and its activating kinase p38MAPK form a tight nuclear complex in resting cells (Ben-Levy et al., 1995,
1998; ter Haar et al., 2007). MK2 contains a nuclear localization signal (NLS) and a nuclear export signal (NES) located at the C-terminus. At resting state, the NES is masked by a direct intramolecular interaction (ter Haar et al., 2007). Following p38mediated activating phosphorylation of MK2 on Thr-334, this interaction is relieved and the NES becomes exposed, resulting in cytoplasmic translocation of the p38MAPK/MK2 complex (BenLevy et al., 1995, 1998; ter Haar et al., 2007). We could show that MK2 rapidly leaves the nucleus in response to DNA damage via a Crm1-dependent nuclear export mechanism (Reinhardt et al., 2010). Thus, we hypothesized that late cytoplasmic MK2 activity might be required to maintain $\mathrm{Cdc} 25 \mathrm{~B} / \mathrm{C}$ sequestered in the cytoplasm in the context of active cell cycle checkpoints. We have hence used live cell imaging to follow the subcellular distribution of Cdc25B and C after genotoxic stress in control cells or cells that were depleted of either Chk1 or MK2. Cytoplasmic accumulation of GFP-tagged Cdc25B/C was used as a readout for active checkpoint signaling. These experiments revealed that adriamycin exposure induces a robust cell cycle checkpoint in control cells that is relieved after $\sim 30 \mathrm{~h}$ and is followed by a cytologically normal mitotic cell division. Cdc25B/C was maintained in the cytoplasm until cells entered mitosis. In contrast, Chk1 depletion resulted in premature nuclear re-entry of Cdc $25 \mathrm{~B} / \mathrm{C}$ after $\sim 15 \mathrm{~h}$, followed by catastrophic mitotic cell division resulting in apoptosis. We observed a similar phenotype in MK2-depleted cells. However, Cdc25B/C nuclear re-entry did not occur until $\sim 23 \mathrm{~h}$ following doxorubicin. Intriguingly in this regard is the observation that this time corresponds perfectly to the time when MK2 activity returned to baseline levels in Gadd $45 \alpha$-depleted cells that were treated with doxorubicin. These data strongly suggest that the positive feedback loop involving MK2-dependent stabilization of Gadd $45 \alpha$, and Gadd $45 \alpha$-dependent maintenance of MK2 activity, are essential for prolonged cell cycle arrest through cytoplasmic Cdc25B/C sequestration in response to adriamycin. Together, these data suggest that a feed forward loop consisting of $\mathrm{p} 38, \mathrm{MK} 2$, and Gadd $45 \alpha$ is critical to provide time to recover from adriamycin-induced genotoxic insults before entering the next mitotic cell division.

\section{CONCLUDING REMARKS}

Posttranscriptional control of gene expression has recently moved into the focus of scientists working in various areas of life sciences. This is owed to the discovery of miRNA-mediated gene silencing mechanisms and the uncovering and characterization of a number of RBPs that are involved in the stabilization and translatability of mRNAs. The DDR network has classically been regarded as consisting of a fast-acting kinase signaling branch, leading to the rapid inactivation of Cdk-cyclin complexes and a delayed transcriptional response, resulting in the transactivation of genes encoding for Cdk inhibitors, such a p21. As a consequence of numerous recent discoveries, a clearer picture is emerging stressing the molecular mechanisms involved in posttranscriptional control of gene expression and expanding the complex DDR signaling network with a third layer. These recent reports strongly suggest that cells employ complex regulatory circuits impacting on transcript stability and translatability in response to genotoxic stress. The major challenges in this emerging area of research in the field of DNA damage signaling 
are the identification of transcripts that are posttranscriptionally regulated and the identification and functional characterization of proteins that mediate this posttranscriptional control. New technologies, such as, genome-wide RNAi screening and next generation sequencing of cell lines and primary tumor material will promote the identification and functional characterization of non-coding RNAs, RBP, and regulatory RNA sequences involved in the initiation, maintenance and termination of DDR signaling in human tissue.

\section{REFERENCES}

Abdelmohsen, K., Pullmann, R. Jr., Lal, A., Kim, H. H., Galban, S., Yang, X., Blethrow, J. D., Walker, M., Shubert, J., Gillespie, D. A., Furneaux, H., and Gorospe, M. (2007). Phosphorylation of HuR by Chk2 regulates SIRT1 expression. Mol. Cell 25, 543-557.

Abdelmohsen, K., Srikantan, S., Tominaga, K., Kang, M. J., Yaniv, Y., Martindale, J. L., Yang, X., Park, S. S., Becker, K. G., Subramanian, M., Maudsley, S., Lal, A., and Gorospe, M. (2012). Growth Inhibition by miR-519 via Multiple p21-Inducing Pathways. Mol. Cell. Biol. 32, 2530-2548.

Abraham, R. T. (2001). Cell cycle checkpoint signaling through the ATM and ATR kinases. Genes Dev. 15, 2177-2196.

Amundson, S. A., Patterson, A., Do, K. T., and Fornace, A. J. Jr. (2002). A nucleotide excision repair master-switch: p53 regulated coordinate induction of global genomic repair genes. Cancer Biol. Ther. 1, 145-149.

Amundson, S. A., Zhan, Q., Penn, L. Z., and Fornace, A. J. Jr. (1998). Myc suppresses induction of the growth arrest genes gadd34, gadd45, and gadd 153 by DNA-damaging agents. Oncogene 17, 2149-2154.

Anderson, P., and Kedersha, N. (2002). Stressful initiations. J. Cell. Sci. 115, 3227-3234.

Anderson, P., and Kedersha, N. (2006). RNA granules. J. Cell Biol. 172, 803-808.

Barreto, G., Schafer, A., Marhold, J., Stach, D., Swaminathan, S. K., Handa, V., Doderlein, G., Maltry, N., Wu, W., Lyko, F., and Niehrs, C. (2007). Gadd45a promotes epigenetic gene activation by repairmediated DNA demethylation. Nature 445, 671-675.

Bartek, J., and Lukas, J. (2003). Chk1 and Chk2 kinases in checkpoint control and cancer. Cancer Cell 3, 421-429.

Ben-Levy, R., Hooper, S., Wilson, R., Paterson, H. F., and Marshall, C. J. (1998). Nuclear export of the stress-activated protein kinase p38 mediated by its substrate MAPKAP kinase-2. Curr. Biol. 8, 1049-1057.

Ben-Levy, R., Leighton, I. A., Doza, Y. N., Attwood, P., Morrice, N., Marshall, C. J., and Cohen, P. (1995). Identification of novel phosphorylation sites required for activation of MAPKAP kinase-2. EMBO J. 14, 5920-5930.

Bollig, F., Winzen, R., Gaestel, M., Kostka, S., Resch, K., and Holtmann, H. (2003). Affinity purification of ARE-binding proteins identifies polyA-binding protein 1 as a potential substrate in MK2-induced mRNA stabilization. Biochem. Biophys. Res. Commun. 301, 665-670.

Bommer, G. T., Gerin, I., Feng, Y., Kaczorowski, A. J., Kuick, R., Love, R. E., Zhai, Y., Giordano, T. J., Qin, Z. S., Moore, B. B., MacDougald, O. A., Cho, K. R., and Fearon, E. R. (2007). p53-mediated activation of miRNA34 candidate tumorsuppressor genes. Curr. Biol. 17, 1298-1307.

Buchan, J. R., and Parker, R. (2009). Eukaryotic stress granules: the ins and outs of translation. Mol. Cell 36, 932-941.

Bulavin, D. V., Higashimoto, Y., Popoff, I. J., Gaarde, W. A., Basrur, V., Potapova, O., Appella, E., and Fornace, A. J. Jr. (2001). Initiation of a G2/M checkpoint after ultraviolet radiation requires p38 kinase. Nature 411, 102-107.

Bulavin, D. V., Kovalsky, O., Hollander, M. C., and Fornace, A. J. Jr. (2003). Loss of oncogenic H-ras-induced cell cycle arrest and p38 mitogenactivated protein kinase activation by disruption of Gadd45a. Mol. Cell. Biol. 23, 3859-3871.

Bush, A., Mateyak, M., Dugan, K., Obaya, A., Adachi, S., Sedivy, J., and Cole, M. (1998). c-myc null cells misregulate cad and gadd45 but not other proposed c-Myc targets. Genes Dev. 12, 3797-3802.

Calin, G. A., Dumitru, C. D., Shimizu, M., Bichi, R., Zupo, S., Noch, E., Aldler, H., Rattan, S., Keating, M., Rai, K., Rassenti, L., Kipps,

\section{ACKNOWLEDGMENTS}

We apologize to our colleagues for the omission of many important contributions to the field, and their references, due to space limitations. We thank the members of the Reinhardt laboratory for helpful discussions. This work was supported by the Deutsche Forschungsgemeinschaft (RE2246/1-1, RE2246/2-1, SFB-829, and SFB-832 to H. Christian Reinhardt), the Deutsche Nierenstiftung (to Katja Höpker) and the Köln Fortune Program (to Grit S. Herter-Sprie and Katja Höpker).

T., Negrini, M., Bullrich, F., and Croce, C. M. (2002). Frequent deletions and down-regulation of micro- RNA genes miR15 and miR16 at 13q14 in chronic lymphocytic leukemia. Proc. Natl. Acad. Sci. U.S.A. 99, 15524-15529.

Calin, G. A., Sevignani, C., Dumitru, C. D., Hyslop, T., Noch, E., Yendamuri, S., Shimizu, M., Rattan, S., Bullrich, F., Negrini, M., and Croce, C. M. (2004). Human microRNA genes are frequently located at fragile sites and genomic regions involved in cancers. Proc. Natl. Acad. Sci. U.S.A. 101, 2999-3004.

Cannell, I. G., and Bushell, M. (2010). Regulation of Myc by miR-34c: a mechanism to prevent genomic instability? Cell Cycle 9, 2726-2730.

Cannell, I. G., Kong, Y. W., and Bushell, M. (2008). How do microRNAs regulate gene expression? Biochem. Soc. Trans. 36, 1224-1231.

Cannell, I. G., Kong, Y. W., Johnston, S. J., Chen, M. L., Collins, H. M., Dobbyn, H. C., Elia, A., Kress, T. R., Dickens, M., Clemens, M. J., Heery, D. M., Gaestel, M., Eilers, M., Willis, A. E., and Bushell, M. (2010). p38 MAPK/MK2-mediated induction of miR-34c following DNA damage prevents Myc-dependent DNA replication. Proc. Natl. Acad. Sci. U.S.A. 107, 5375-5380.

Castello, A., Fischer, B., Eichelbaum, K., Horos, R., Beckmann, B. M., Strein, C., Davey, N. E., Humphreys, D. T., Preiss, T., Steinmetz, L. M., Krijgsveld, J., and Hentze, M. W. (2012). Insights into RNA Biology from an Atlas of Mammalian mRNA-Binding Proteins. Cell 149, 1393-1406.

Chang, T. C., Wentzel, E. A., Kent, O. A., Ramachandran, K., Mullendore, M., Lee, K. H., Feldmann, G., Yamakuchi, M., Ferlito, M., Lowenstein, C. J., Arking, D. E., Beer, M. A., Maitra, A., and Mendell, J. T. (2007). Transactivation of miR-34a by $\mathrm{p} 53$ broadly influences gene expression and promotes apoptosis. Mol. Cell 26, 745-752.
Chen, C. Y., and Shyu, A. B. (1994). Selective degradation of earlyresponse-gene mRNAs: functional analyses of sequence features of the AU-rich elements. Mol. Cell. Biol. 14, 8471-8482.

Constance, C. M., Morgan J. I. T., and Umek, R. M. (1996). C/EBPalpha regulation of the growth-arrestassociated gene gadd45. Mol. Cell. Biol. 16, 3878-3883.

Cooper, T. A., Wan, L., and Dreyfuss, G. (2009). RNA and disease. Cell 136, 777-793.

Corney, D. C., Flesken-Nikitin, A., Godwin, A. K., Wang, W., and Nikitin, A. Y. (2007). MicroRNA$34 \mathrm{~b}$ and MicroRNA-34c are targets of p53 and cooperate in control of cell proliferation and adhesionindependent growth. Cancer Res. 67, 8433-8438.

Darnell, R. B. (2010). RNA regulation in neurologic disease and cancer. Cancer Res. Treat. 42, 125-129.

Dean, J. L., Sully, G., Clark, A. R., and Saklatvala, J. (2004). The involvement of AU-rich element-binding proteins in p38 mitogen-activated protein kinase pathway-mediated mRNA stabilisation. Cell. Signal. 16, 1113-1121.

Donzelli, M., and Draetta, G. F. (2003). Regulating mammalian checkpoints through Cdc25 inactivation. EMBO Rep. 4, 671-677.

el-Deiry, W. S., Tokino, T., Velculescu, V. E., Levy, D. B., Parsons, R., Trent, J. M., Lin, D., Mercer, W. E., Kinzler, K. W., and Vogelstein, B. (1993). WAF1, a potential mediator of p53 tumor suppression. Cell 75, 817-825.

Esteller, M. (2011). Non-coding RNAs in human disease. Nat. Rev. Genet. 12, 861-874.

Fan, J., Yang, X., Wang, W., Wood, W. H. 3rd., Becker, K. G., and Gorospe, M. (2002). Global analysis of stressregulated mRNA turnover by using cDNA arrays. Proc. Natl. Acad. Sci. U.S.A. 99, 10611-10616.

Fiscella, M., Zhang, H., Fan, S., Sakaguchi, K., Shen, S., Mercer, W. E., Vande Woude, G. F., O'Connor, P. M., and Appella, E. (1997). Wip1, 
a novel human protein phosphatase that is induced in response to ionizing radiation in a p53-dependent manner. Proc. Natl. Acad. Sci. U.S.A. 94, 6048-6053.

Gasch, A. P., Huang, M., Metzner, S., Botstein, D., Elledge, S. J., and Brown, P. O. (2001). Genomic expression responses to DNA-damaging agents and the regulatory role of the yeast ATR homolog Meclp. Mol. Biol. Cell 12, 2987-3003.

Goodarzi, H., Najafabadi, H. S., Oikonomou, P., Greco, T. M., Fish, L., Salavati, R., Cristea, I. M., and Tavazoie, S. (2012). Systematic discovery of structural elements governing stability of mammalian messenger RNAs. Nature 485, 264-268.

Guo, H., Ingolia, N. T., Weissman, J. S., and Bartel, D. P. (2010). Mammalian microRNAs predominantly act to decrease target mRNA levels. Nature 466, 835-840.

Hafner, M., Landthaler, M., Burger, L., Khorshid, M., Hausser, J., Berninger, P., Rothballer, A., Ascano, M. Jr., Jungkamp, A. C., Munschauer, M., Ulrich, A., Wardle, G. S., Dewell, S., Zavolan, M., and Tuschl, T. (2010). Transcriptomewide identification of RNA-binding protein and microRNA target sites by PAR-CLIP. Cell 141, 129-141.

Harper, J. W., and Elledge, S. J. (2007). The DNA damage response: ten years after. Mol. Cell 28, 739-745.

He, L., He, X., Lim, L. P., de Stanchina, E., Xuan, Z., Liang, Y., Xue, W., Zender, L., Magnus, J., Ridzon, D., Jackson, A. L., Linsley, P. S., Chen, C., Lowe, S. W., Cleary, M. A., and Hannon, G. J. (2007). A microRNA component of the p53 tumour suppressor network. Nature 447, 1130-1134.

Hildesheim, J., Bulavin, D. V., Anver, M. R., Alvord, W. G., Hollander, M. C., Vardanian, L., and Fornace, A. J. Jr. (2002). Gadd45a protects against UV irradiation-induced skin tumors, and promotes apoptosis and stress signaling via MAPK and p53. Cancer Res. 62, 7305-7315.

Hirose, T., Sowa, Y., Takahashi, S., Saito, S., Yasuda, C., Shindo, N., Furuichi, K., and Sakai, T. (2003). p53-independent induction of Gadd 45 by histone deacetylase inhibitor: coordinate regulation by transcription factors Oct- 1 and NF-Y. Oncogene 22, 7762-7773.

Hollander, M. C., Sheikh, M. S., Bulavin, D. V., Lundgren, K., Augeri-Henmueller, L., Shehee, R., Molinaro, T. A., Kim, K. E., Tolosa, E., Ashwell, J. D., Rosenberg, M. P.,
Zhan, Q., Fernandez-Salguero, P. M., Morgan, W. F., Deng, C. X., and Fornace, A. J. Jr. (1999). Genomic instability in Gadd45a-deficient mice. Nat. Genet. 23, 176-184.

Huarte, M., Guttman, M., Feldser, D., Garber, M., Koziol, M. J., Kenzelmann-Broz, D., Khalil, A. M., Zuk, O., Amit, I., Rabani, M., Attardi, L. D., Regev, A., Lander, E. S., Jacks, T., and Rinn, J. L. (2010). A large intergenic noncoding RNA induced by $\mathrm{p} 53$ mediates global gene repression in the p53 response. Cell 142, 409-419.

Jackman, J., Alamo, I. Jr., and Fornace, A. J. Jr. (1994). Genotoxic stress confers preferential and coordinate messenger RNA stability on the five gadd genes. Cancer Res. 54, 5656-5662.

Jackson, S. P., and Bartek, J. (2009). The DNA-damage response in human biology and disease. Nature 461, 1071-1078.

Jazayeri, A., Falck, J., Lukas, C., Bartek, J., Smith, G. C., Lukas, J., and Jackson, S. P. (2006). ATM- and cell cycle-dependent regulation of ATR in response to DNA doublestrand breaks. Nat. Cell Biol. 8, 37-45.

Jiang, H., Reinhardt, H. C., Bartkova, J., Tommiska, J., Blomqvist, C., Nevanlinna, H., Bartek, J., Yaffe, M. B., and Hemann, M. T. (2009). The combined status of ATM and p53 link tumor development with therapeutic response. Genes Dev. 23, 1895-1909.

Jin, J., Shirogane, T., Xu, L., Nalepa, G., Qin, J., Elledge, S. J., and Harper, J. W. (2003). SCFbeta-TRCP links Chk1 signaling to degradation of the Cdc25A protein phosphatase. Genes Dev. 17, 3062-3074.

Jin, S., Fan, F., Fan, W., Zhao, H., Tong, T., Blanck, P., Alomo, I., Rajasekaran, B., and Zhan, Q. (2001). Transcription factors Oct-1 and NF-YA regulate the p53-independent induction of the GADD45 following DNA damage. Oncogene 20, 2683-2690.

Kastan, M. B., and Lim, D. S. (2000). The many substrates and functions of ATM. Nat. Rev. Mol. Cell Biol. 1, 179-186.

Kastan, M. B., Zhan, Q., el-Deiry, W. S., Carrier, F., Jacks, T., Walsh, W. V., Plunkett, B. S., Vogelstein, B., and Fornace, A. J. Jr. (1992). A mammalian cell cycle checkpoint pathway utilizing p53 and GADD45 is defective in ataxia-telangiectasia. Cell 71, 587-597.

Kedersha, N., and Anderson, P. (2002). Stress granules: sites of mRNA triage that regulate mRNA stability and translatability. Biochem. Soc. Trans. 30, 963-969.

Kedersha, N., Stoecklin, G., Ayodele, M., Yacono, P., Lykke-Andersen, J., Fritzler, M. J., Scheuner, D., Kaufman, R. J., Golan, D. E. and Anderson, P. (2005). Stress granules and processing bodies are dynamically linked sites of mRNP remodeling. J. Cell Biol. 169, 871-884.

Khalil, A. M., Guttman, M., Huarte, M., Garber, M., Raj, A., Rivea Morales, D., Thomas, K., Presser, A., Bernstein, B. E., van Oudenaarden, A., Regev, A., Lander, E. S., and Rinn, J. L. (2009). Many human large intergenic noncoding RNAs associate with chromatinmodifying complexes and affect gene expression. Proc. Natl. Acad. Sci. U.S.A. 106, 11667-11672.

Kim, H. H., Abdelmohsen, K., Lal, A., Pullmann, R. Jr., Yang, X., Galban, S., Srikantan, S., Martindale, J. L., Blethrow, J., Shokat, K. M., and Gorospe, M. (2008). Nuclear HuR accumulation through phosphorylation by Cdk1. Genes Dev. 22, 1804-1815.

Lafarga, V., Cuadrado, A., Lopez de Silanes, I., Bengoechea, R., Fernandez-Capetillo, O., and Nebreda, A. R. (2009). p38 Mitogen-activated protein kinaseand HuR-dependent stabilization of p21(Cip1) mRNA mediates the G(1)/S checkpoint. Mol. Cell. Biol. 29, 4341-4351.

Lal, A., Abdelmohsen, K., Pullmann, R., Kawai, T., Galban, S., Yang, X., Brewer, G., and Gorospe, M. (2006). Posttranscriptional derepression of GADD45alpha by genotoxic stress. Mol. Cell 22, 117-128.

Lopez-Aviles, S., Grande, M., Gonzalez, M., Helgesen, A. L., Alemany, V., Sanchez-Piris, M., Bachs, O., Millar, J. B., and Aligue, R. (2005). Inactivation of the $\mathrm{Cdc} 25$ phosphatase by the stress-activated Srk1 kinase in fission yeast. Mol. Cell 17, 49-59.

Lu, X., Nguyen, T. A., and Donehower, L. A. (2005). Reversal of the ATM/ATR-mediated DNA damage response by the oncogenic phosphatase PPM1D. Cell Cycle 4, 1060-1064.

Lukong, K. E., Chang, K. W., Khandjian, E. W., and Richard, S. (2008). RNA-binding proteins in human genetic disease. Trends Genet. 24, 416-425.

Maitra, S., Chou, C. F., Luber, C. A., Lee, K. Y., Mann, M., and Chen, C. Y. (2008). The AU-rich element mRNA decay-promoting activity of
BRF1 is regulated by mitogenactivated protein kinase-activated protein kinase 2. RNA 14, 950-959.

Manke, I. A., Nguyen, A., Lim, D., Stewart, M. Q., Elia, A. E., and Yaffe, M. B. (2005). MAPKAP kinase-2 is a cell cycle checkpoint kinase that regulates the $\mathrm{G} 2 / \mathrm{M}$ transition and $S$ phase progression in response to UV irradiation. Mol. Cell 17, 37-48.

Marchese, F. P., Aubareda, A., Tudor, C., Saklatvala, J., Clark, A. R., and Dean, J. L. (2010). MAPKAP kinase 2 blocks tristetraprolin-directed mRNA decay by inhibiting CAF1 deadenylase recruitment. J. Biol. Chem. 285, 27590-27600.

Marhin, W. W., Chen, S., Facchini, L. M., Fornace, A. J. Jr., and Penn, L. Z. (1997). Myc represses the growth arrest gene gadd45. Oncogene 14, 2825-2834.

Matsuoka, S., Ballif, B. A. Smogorzewska, A., McDonald, E. R. 3rd., Hurov, K. E., Luo, J., Bakalarski, C. E., Zhao, Z., Solimini, N., Lerenthal, Y., Shiloh, Y., Gygi, S. P., and Elledge, S. J. (2007). ATM and ATR substrate analysis reveals extensive protein networks responsive to DNA damage. Science 316, 1160-1166.

Meyer, S., Temme, C., and Wahle, E. (2004). Messenger RNA turnover in eukaryotes: pathways and enzymes. Crit. Rev. Biochem. Mol. Biol. 39, 197-216.

Mitchell, P., and Tollervey, D. (2000). mRNA stability in eukaryotes. Curr. Opin. Genet. Dev.10, 193-198.

Moore, M. J. (2005). From birth to death: the complex lives of eukaryotic mRNAs. Science 309, 1514-1518.

Orphanides, G., and Reinberg, D. (2002). A unified theory of gene expression. Cell 108, 439-451.

Paulsen, R. D., Soni, D. V., Wollman, R., Hahn, A. T., Yee, M. C., Guan, A., Hesley, J. A., Miller, S. C., Cromwell, E. F., Solow-Cordero, D. E., Meyer, T., and Cimprich, K. A. (2009). A genome-wide siRNA screen reveals diverse cellular processes and pathways that mediate genome stability. Mol. Cell 35, 228-239.

Pothof, J., Verkaik, N. S., van, I. W., Wiemer, E. A., Ta, V. T., van der Horst, G. T., Jaspers, N. G., van Gent, D. C., Hoeijmakers, J. H., and Persengiev, S. P. (2009). MicroRNA-mediated gene silencing modulates the UV-induced DNAdamage response. EMBO J. 28, 2090-2099.

Raman, M., Earnest, S., Zhang, K., Zhao, Y., and Cobb, M. H. (2007). TAO kinases mediate activation of 
p38 in response to DNA damage. EMBO J. 26, 2005-2014.

Raver-Shapira, N., Marciano, E., Meiri, E., Spector, Y., Rosenfeld, N., Moskovits, N., Bentwich, Z., and Oren, M. (2007). Transcriptional activation of miR-34a contributes to p53-mediated apoptosis. Mol. Cell 26, 731-743.

Reinhardt, H. C., Aslanian, A. S., Lees, J. A., and Yaffe, M. B. (2007). p53deficient cells rely on ATM- and ATR-mediated checkpoint signaling through the p38MAPK/MK2 pathway for survival after DNA damage. Cancer Cell 11, 175-189.

Reinhardt, H. C., Cannell, I. G., Morandell, S., and Yaffe, M. B. (2011). Is post-transcriptional stabilization, splicing and translation of selective mRNAs a key to the DNA damage response? Cell Cycle 10, 23-27.

Reinhardt, H. C., Hasskamp, P., Schmedding, I., Morandell, S., van Vugt, M. A. T. M., Wang, X., Linding, R., Ong, S.-E., Weaver, D., Carr, S. A., and Yaffe, M. B. (2010). DNA Damage Activates a Spatially Distinct Late Cytoplasmic Cell-Cycle Checkpoint Network Controlled by MK2-Mediated RNA Stabilization. Mol. Cell 40, 34-49.

Reinhardt, H. C., Jiang, H., Hemann, M. T., and Yaffe, M. B. (2009). Exploiting synthetic lethal interactions for targeted cancer therapy. Cell Cycle 8, 3112-3119.

Reinhardt, H. C., and Yaffe, M. B. (2009). Kinases that control the cell cycle in response to DNA damage: Chk1, Chk2, and MK2. Curr. Opin. Cell Biol. 21, 245-255.

Rieger, K. E., and Chu, G. (2004). Portrait of transcriptional responses to ultraviolet and ionizing radiation in human cells. Nucleic Acids Res. 32, 4786-4803.

Rockx, D. A., Mason, R., van Hoffen, A., Barton, M. C., Citterio, E., Bregman, D. B., van Zeeland, A. A., Vrieling, H., and Mullenders, L. H. (2000). UV-induced inhibition of transcription involves repression of transcription initiation and phosphorylation of RNA polymerase II. Proc. Natl. Acad. Sci. U.S.A. 97, 10503-10508.

Rousseau, S., Morrice, N., Peggie, M., Campbell, D. G., Gaestel, M., and Cohen, P. (2002). Inhibition of SAPK2a/p38 prevents hnRNP A0 phosphorylation by MAPKAP-K2 and its interaction with cytokine mRNAs. EMBO J. 21, 6505-6514.

Rudolph, J. (2007). Cdc25 phosphatases: structure, specificity, and mechanism. Biochemistry 46, 3595-3604.
Shaw, G., and Kamen, R. (1986). A conserved $\mathrm{AU}$ sequence from the $3^{\prime}$ untranslated region of GM-CSF mRNA mediates selective mRNA degradation. Cell 46, 659-667.

Shiloh, Y. (2001). ATM and ATR: networking cellular responses to DNA damage. Curr. Opin. Genet. Dev. 11, 71-77.

Shiloh, Y. (2003). ATM and related protein kinases: safeguarding genome integrity. Nat. Rev. Cancer 3, 155-168.

Shreeram, S., Demidov, O. N., Hee, W. K., Yamaguchi, H., Onishi, N., Kek, C., Timofeev, O. N., Dudgeon, C., Fornace, A. J., Anderson, C. W., Minami, Y., Appella, E., and Bulavin, D. V. (2006). Wipl phosphatase modulates ATM-dependent signaling pathways. Mol. Cell 23, 757-764.

Smith, M. L., Ford, J. M., Hollander, M. C., Bortnick, R. A., Amundson, S. A., Seo, Y. R., Deng, C. X., Hanawalt, P. C., and Fornace, A. J. Jr. (2000). p53-mediated DNA repair responses to UV radiation: studies of mouse cells lacking p53, p21, and/or gadd45 genes. Mol. Cell. Biol. 20, 3705-3714.

Stoecklin, G., Stubbs, T., Kedersha, N., Wax, S., Rigby, W. F., Blackwell, T. K., and Anderson, P. (2004). MK2-induced tristetraprolin:14-3-3 complexes prevent stress granule association and ARE-mRNA decay. EMBO J. 23, 1313-1324.

Suzuki, H. I., Yamagata, K., Sugimoto, K., Iwamoto, T., Kato, S., and Miyazono, K. (2009). Modulation of microRNA processing by p53. Nature 460, 529-533.

Svejstrup, J. Q. (2002). Mechanisms of transcription-coupled DNA repair. Nat. Rev. Mol. Cell Biol. 3, 21-29.

Takahashi, S., Saito, S., Ohtani, N., and Sakai, T. (2001). Involvement of the Oct-1 regulatory element of the gadd 45 promoter in the p53-independent response to ultraviolet irradiation. Cancer Res. 61, 1187-1195.

Takekawa, M., Adachi, M., Nakahata, A., Nakayama, I., Itoh, F., Tsukuda, H., Taya, Y., and Imai, K. (2000). p53-inducible wip1 phosphatase mediates a negative feedback regulation of p38 MAPK-p53 signaling in response to UV radiation. EMBO J. 19, 6517-6526.

Tan, W., Zheng, L., Lee, W. H., and Boyer, T. G. (2004). Functional dissection of transcription factor ZBRK1 reveals zinc fingers with dual roles in DNA-binding and BRCA1-dependent transcriptional repression. J. Biol. Chem. 279, 6576-6587.
Tarasov, V., Jung, P., Verdoodt, B., Lodygin, D., Epanchintsev, A., Menssen, A., Meister, G., and Hermeking, H. (2007). Differential regulation of microRNAs by p53 revealed by massively parallel sequencing: miR-34a is a p53 target that induces apoptosis and G1-arrest. Cell Cycle 6, 1586-1593.

ter Haar, E., Prabhakar, P., Liu, X., and Lepre, C. (2007). Crystal structure of the p38 alpha-MAPKAP kinase 2 heterodimer. J. Biol. Chem. 282, 9733-9739.

Thyss, R., Virolle, V., Imbert, V., Peyron, J. F., Aberdam, D., and Virolle, T. (2005). NF-kappaB/Egr$1 /$ Gadd45 are sequentially activated upon UVB irradiation to mediate epidermal cell death. EMBO J. 24, 128-137.

Tran, H., Brunet, A., Grenier, J. M., Datta, S. R., Fornace, A. J. Jr., DiStefano, P. S., Chiang, L. W., and Greenberg, M. E. (2002). DNA repair pathway stimulated by the forkhead transcription factor FOXO3a through the Gadd45 protein. Science 296, 530-534.

Tran, H., Maurer, F., and Nagamine, Y. (2003). Stabilization of urokinase and urokinase receptor mRNAs by $\mathrm{HuR}$ is linked to its cytoplasmic accumulation induced by activated mitogen-activated protein kinase-activated protein kinase 2. Mol. Cell. Biol. 23, 7177-7188.

Vichi, P., Coin, F., Renaud, J. P., Vermeulen, W., Hoeijmakers, J. H., Moras, D., and Egly, J. M. (1997). Cisplatin- and UV-damaged DNA lure the basal transcription factor TFIID/TBP. EMBO J. 16 , 7444-7456.

Wang, P., Zou, F., Zhang, X., Li, H., Dulak, A., Tomko, R. J. Jr., Lazo, J. S., Wang, Z., Zhang, L., and Yu, J. (2009). microRNA21 negatively regulates $\mathrm{Cdc} 25 \mathrm{~A}$ and cell cycle progression in colon cancer cells. Cancer Res. 69, 8157-8165.

Wang, W., Furneaux, H., Cheng, H., Caldwell, M. C., Hutter, D., Liu, Y., Holbrook, N., and Gorospe, M. (2000). HuR regulates p21 mRNA stabilization by UV light. Mol. Cell. Biol. 20, 760-769.

Wang, X. W., Zhan, Q., Coursen, J. D., Khan, M. A., Kontny, H. U., Yu, L., Hollander, M. C., O’Connor, P. M., Fornace, A. J. Jr., and Harris, C. C. (1999). GADD45 induction of a G2/M cell cycle checkpoint. Proc. Natl. Acad. Sci. U.S.A. 96, 3706-3711.
Wei, W., Ba, Z., Gao, M., Wu, Y., Ma, Y., Amiard, S., and White, C. I., Rendtlew Danielsen, J. M., Yang, Y. G., and Qi, Y. (2012). A role for small RNAs in DNA double-strand break repair. Cell 149, 101-112.

Wilker, E. W., van Vugt, M. A., Artim, S. A., Huang, P. H., Petersen, C. P., Reinhardt, H. C., Feng, Y., Sharp, P. A., Sonenberg, N., White, F. M., and Yaffe, M. B. (2007). 14-33sigma controls mitotic translation to facilitate cytokinesis. Nature 446, 329-332.

Wilson, G. M., Lu, J., Sutphen, K., Suarez, Y., Sinha, S., Brewer, B., Villanueva-Feliciano, E. C., Ysla, R. M., Charles, S., and Brewer, G. (2003). Phosphorylation of p40AUF1 regulates binding to $\mathrm{A}+$ U-rich mRNA-destabilizing elements and protein-induced changes in ribonucleoprotein structure. J. Biol. Chem. 278, 33039-33048.

Wilson, T., and Treisman, R. (1988). Removal of poly(A) and consequent degradation of c-fos mRNA facilitated by $3^{\prime} \mathrm{AU}$-rich sequences. Nature 336, 396-399.

$\mathrm{Xu}$, N., Chen, C. Y., and Shyu, A. B. (1997). Modulation of the fate of cytoplasmic mRNA by AU-rich elements: key sequence features controlling mRNA deadenylation and decay. Mol. Cell. Biol. 17, 4611-4621.

Yamakuchi, M., Ferlito, M., and Lowenstein, C. J. (2008). miR-34a repression of SIRT1 regulates apoptosis. Proc. Natl. Acad. Sci. U.S.A. 105, 13421-13426.

Zeng, Y., Sankala, H., Zhang, X., and Graves, P. R. (2008). Phosphorylation of Argonaute 2 at serine-387 facilitates its localization to processing bodies. Biochem. J. 413, 429-436.

Zhan, Q. (2005). Gadd45a, a p53- and BRCA1-regulated stress protein, in cellular response to DNA damage. Mutat. Res. 569, 133-143.

Zhan, Q., Chen, I. T., Antinore, M. J., and Fornace, A. J. Jr. (1998). Tumor suppressor p53 can participate in transcriptional induction of the GADD45 promoter in the absence of direct DNA binding. Mol. Cell. Biol. 18, 2768-2778.

Zhang, C., and Darnell, R. B. (2011). Mapping in vivo protein-RNA interactions at single-nucleotide resolution from HITS-CLIP data. Nat. Biotechnol. 29, 607-614.

Zhang, W., Wagner, B. J., Ehrenman, K., Schaefer, A. W., DeMaria, C. T., Crater, D., DeHaven, K., Long, L., and Brewer, G. (1993). 
Purification, characterization, and cDNA cloning of an AU-rich element RNA-binding protein, AUF1. Mol. Cell. Biol. 13, 7652-7665.

Zhang, X., Wan, G., Mlotshwa, S., Vance, V., Berger, F. G., Chen, H., and $\mathrm{Lu}, \mathrm{X}$. (2010). Oncogenic Wip1 phosphatase is inhibited by miR-16 in the DNA damage signaling pathway. Cancer Res. 70, 7176-7186.

Zheng, L., Pan, H., Li, S., FleskenNikitin, A., Chen, P. L., Boyer, T. G., and Lee, W. H. (2000). Sequencespecific transcriptional corepressor function for BRCA1 through a novel zinc finger protein, ZBRK1. Mol. Cell 6, 757-768.

Zhou, B. B., and Elledge, S. J. (2000). The DNA damage response: putting checkpoints in perspective. Nature 408, 433-439.

Conflict of Interest Statement: The authors declare that the research was conducted in the absence of any commercial or financial relationships that could be construed as a potential conflict of interest.

Received: 26 July 2012; accepted: 06 August 2012; published online: 25 August 2012.

Citation: Boucas J, Riabinska A, Jokic M, Herter-Sprie GS, Chen S, Höpker K and Reinhardt HC (2012) Posttranscriptional regulation of gene expression-adding another layer of complexity to the DNA damage response. Front. Gene. 3:159. doi: 10.3389/fgene. 2012.00159
This article was submitted to Frontiers in Cancer Genetics, a specialty of Frontiers in Genetics.

Copyright (c) 2012 Boucas, Riabinska, Jokic, Herter-Sprie, Chen, Höpker and Reinhardt. This is an open-access article distributed under the terms of the Creative Commons Attribution License, which permits use, distribution and reproduction in other forums, provided the original authors and source are credited and subject to any copyright notices concerning any third-party graphics etc. 